\title{
Comparative analysis of dinoflagellate chloroplast genomes reveals rRNA and tRNA genes
}

\author{
Adrian C Barbrook*1, Nicole Santucci ${ }^{2}$, Lindsey J Plenderleith ${ }^{1}$, \\ Roger G Hiller ${ }^{3}$ and Christopher J Howe ${ }^{1}$
}

Address: ${ }^{1}$ Department of Biochemistry, University of Cambridge, Downing Site, Tennis Court Road, Cambridge, CB2 1QW, UK, ${ }^{2} \mathrm{Children's}$ Medical Research Institute, 214 Hawkesbury Road, Westmead, Sydney, NSW 2145, Australia and ${ }^{3}$ Department of Biological Sciences, Macquarie University, Sydney, NSW 2109, Australia

Email: Adrian C Barbrook* - acb18@mole.bio.cam.ac.uk; Nicole Santucci - nsantucci@cmri.usyd.edu.au;

Lindsey J Plenderleith - ljp42@cam.ac.uk; Roger G Hiller - rhiller@rna.bio.mq.edu.au; Christopher J Howe - ch26@mole.bio.cam.ac.uk

* Corresponding author

Published: 23 November 2006

BMC Genomics 2006, 7:297 doi:10.1/86/|47|-2/64-7-297
Received: 23 June 2006

Accepted: 23 November 2006

This article is available from: http://www.biomedcentral.com/I47/-2/64/7/297

(c) 2006 Barbrook et al; licensee BioMed Central Ltd.

This is an Open Access article distributed under the terms of the Creative Commons Attribution License (http://creativecommons.org/licenses/by/2.0), which permits unrestricted use, distribution, and reproduction in any medium, provided the original work is properly cited.

\begin{abstract}
Background: Peridinin-containing dinoflagellates have a highly reduced chloroplast genome, which is unlike that found in other chloroplast containing organisms. Genome reduction appears to be the result of extensive transfer of genes to the nuclear genome. Unusually the genes believed to be remaining in the chloroplast genome are found on small DNA 'minicircles'. In this study we present a comparison of sets of minicircle sequences from three dinoflagellate species.

Results: PCR was used to amplify several minicircles from Amphidinium carterae so that a homologous set of gene-containing minicircles was available for Amphidinium carterae and Amphidinium operculatum, two apparently closely related peridinin-containing dinoflagellates. We compared the sequences of these minicircles to determine the content and characteristics of their chloroplast genomes. We also made comparisons with minicircles which had been obtained from Heterocapsa triquetra, another peridinin-containing dinoflagellate. These in silico comparisons have revealed several genetic features which were not apparent in single species analyses. The features include further protein coding genes, unusual rRNA genes, which we show are transcribed, and the first examples of tRNA genes from peridinin-containing dinoflagellate chloroplast genomes.

Conclusion: Comparative analysis of minicircle sequences has allowed us to identify previously unrecognised features of dinoflagellate chloroplast genomes, including additional protein and RNA genes. The chloroplast rRNA gene sequences are radically different from those in other organisms, and in many ways resemble the rRNA genes found in some highly reduced mitochondrial genomes. The retention of certain tRNA genes in the dinoflagellate chloroplast genome has important implications for models of chloroplast-mitochondrion interaction.
\end{abstract}

\section{Background}

The organisation of the chloroplast genome in many peridinin-containing dinoflagellates has been shown to be very unusual [1-5]. A massive reduction in the gene content of the organelle genome is observed in these organisms relative to all other photosynthetic chloroplasts [6]. EST data from a number of dinoflagellate species suggest that many genes that are typically located 
within the chloroplast genome have been transferred to the nuclear genome [7-10]. Furthermore, the genome is unusual in that the remaining chloroplast genes are confined to small circular DNA molecules (minicircles) of between 2-10 kb (although larger molecules have been reported in some species [11]), rather than a single large circularly mapping molecule [12]. The minicircles found in dinoflagellates each typically contain a single gene, though up to three genes have been recorded on one minicircle [13]. An interesting feature of these minicircles is the presence of a non-coding region that is well conserved in all gene-containing minicircles of a given species, as well as in 'empty' minicircles which have no obvious gene sequences [1,3,13-15]. However, even within genera there is little or no conservation of DNA sequence identity within this common non-coding region [16]. In contrast, the coding regions of minicircles show high levels of identity within genera. Some controversy exists as to the location of the minicircles. Several indirect lines of evidence support their location in the chloroplast [5]. These include an absence of sequences encoding transit peptides, the localisation of $p s b A$ transcripts to chloroplasts [17] and chloramphenicol inhibition of PsbA translation [18]. However, a report from one species indicates a possible location of minicircles in the nuclear compartment [4]. This contradiction is not yet resolved, and it remains possible that different dinoflagellate species have circular DNA molecules present in different compartments.

We have characterised what appear to be the complete chloroplast coding genomes of both $A$. carterae and $A$. operculatum as well as a number of the related 'empty' minicircles from each species. It seems likely that few, if any, minicircles remain to be discovered that contain typically chloroplast located genes, since the EST data [7-10] contain examples of almost all the genes which are invariably found on chloroplast genomes that have not been found on minicircles. This provides the basis for a comparative analysis of two sets of minicircles. We have also made comparisons with the other extensively characterised dinoflagellate minicircle set from Heterocapsa triquetra where appropriate. Comparative genome analyses are useful in identifying genetic features that may not be apparent from single genome analyses $[19,20]$. We were particularly interested in examining whether any previously unrecognized genes were present on the minicircles. Genes could have been missed from previous analyses of minicircular sequences, especially if the genes were short or poorly conserved. As the rate of substitution in minicircle genes appears to be high this is a significant concern and similarity searches against sequence databases may have missed genes [2,21]. However, we would expect DNA sequences containing such genes to be conserved between two closely related organisms, such as the two
Amphidinium species. We also used comparisons between more distantly related genera to help establish the extent of ribosomal RNA genes as the identification of rRNA genes has proved controversial [6]. Other pattern based search algorithms, such as tRNA-scan-SE [22], were used to examine the minicircles for significant genetic features.

The results of these analyses suggest that at least three extra protein-coding regions may be present. We also found the first evidence for tRNA genes on minicircles. We have also further characterised rDNA sequences from minicircles. These sequences, which are transcribed, are highly divergent showing evidence of a high rate of mutation, as well as a possible fragmentation of the gene sequence. The peridinin-containing dinoflagellate rDNA sequences share similarities to the reduced rDNA sequences found in mitochondrial genomes.

\section{Results and Discussion \\ PCR amplification of A. carterae minicircles}

A DNA fraction from $A$. carterae which had been previously shown to be enriched in minicircles was used as a template for PCR [3]. Fragments of the A. carterae genes for $p s b B$, petD and $a t p B$ were initially obtained by PCR using degenerate primers based on the corresponding translated gene sequences from A. operculatum and 'universal' primers to the core region (Table 1 ). It was assumed that the gene orientation in A. carterae is conserved with respect to the core region. Part of a $p s b C$ gene sequence was generated by chance from primers CD26f1 and UR (CD26f1 was a primer to reverse of $p s b E$ but had 10 out of $113^{\prime}$ bases in common with $p s b C$ ). Full sequences of each minicircle were generated by adjacent opposed specific primers designed according to the fragment sequences. DNA sequencing revealed that all of the minicircle sequences obtained possessed a core region of the type previously described for A. carterae [3].

Another minicircle was obtained by PCR with primers designed on the basis of the A. carterae core region (UF and UR) only (ecac27: acc. no. DQ507216). A similar approach had been used to obtain nine other empty minicircles [3]. With the characterisation of the four genecoding minicircles from $A$. carterae (petD, atpB, $p s b C$ and $p s b B$ : acc. nos DQ507217-DQ507220 respectively), we now possessed a homologous set of gene-coding minicircle sequences for the two Amphidinium species.

\section{Overall genome characteristics}

A summary of the genome sizes and previously annotated gene content is shown in Table 2. The mean GC contents of the Amphidinium species minicircles are $45.27 \%$ for $A$. carterae and $46.46 \%$ for A. operculatum. The coding regions generally appear to be more GC-rich than the non-coding regions, as shown by a plot of GC content 
Table I: Primers used for PCR and RT-PCR.

\begin{tabular}{|c|c|c|}
\hline Primer & Sequence & Amino acid sequence or adjacent rRNA structure \\
\hline UF & 5'-TTTGGAATCTCAGCTCGATTC & \\
\hline UR & 5'-CTCGCACCCAAATTGACT & \\
\hline CD26fl & 5'-gtGATgagGTCTGtAGTGG & \\
\hline NICpsbB & 5'-GCNTTYTGGCAYTGGGC & AFWHWA \\
\hline petDf3 & 5'-GARCCNGCNTGGCCNAA & EPAWPN \\
\hline atpBrl & 5'-TCNCGGAARTAYTCNGCC & (M) A E Y F R D (in reverse) \\
\hline LSUIF & 5'-AGTGATACTGTTCTCTTGAG & 3' helix 46 LSU rRNA \\
\hline LSU2R & 5'-GGTTTCATAACTCGGTTGTC & 5' helix 62 LSU rRNA \\
\hline LSU3F & 5'-GACAACCGAGTTATGAAACC & 5' helix 62 LSU rRNA \\
\hline LSU4R & 5'-ACGTCCAGTGTCATTTCACC & 5' helix 72 LSU rRNA \\
\hline SSUIF & 5'-GAAACTTAAAGGTGCTGGTGG & 3' helix 27 SSU rRNA \\
\hline SSU2R & 5'-GTTACTAACGATTCCAGCTTC & 5' helix 43 SSU rRNA \\
\hline
\end{tabular}

Primers used to amplify initial fragments of $p s b C$, $p s b B$, petD and atpB genes from $A$. carterae and primers used in RT-PCR analyses of the $A$. operculatum rRNAs. UF (universal forward) and UR (universal reverse) are adjacent opposed primers made to the core region. In CD26fI the mismatches with $p s b C$ sequence are shown in lower case.

(Figure 1). The GC content of all of the core regions in both Amphidinium species is lower than the overall GC content of the minicircles. Intriguingly the $p s b A$ gene in both Amphidinium species is flanked by a region of unusually high GC content preceding the gene and low GC content after the gene. The mean GC content of $H$. triquetra minicircles is $37.02 \%$, which is much lower than in the Amphidinium species. Some of the discrepancy is due to the longer non-coding regions found in the minicircles of $H$. triquetra, as these regions are AT-rich. However, this is not the sole cause. The coding regions of $H$. triquetra, whilst more GC-rich than the core regions, are considerably more AT-rich than the coding regions of Amphidinium. This is reflected in the codon usage of the two genera. Codons ending in A or T are more prevalent in H. triquetra [2]. The total length of all minicircle sequences (both gene-containing and 'empty') obtained from A. carterae is $45,815 \mathrm{bp}$ and from A. operculatum is $34,186 \mathrm{bp}$. The main cause of the difference in lengths is the discovery of many more empty minicircles in A. carterae (10 empty minicircles compared to 5 in A. operculatum). However, in addition the A. carterae minicircles are slightly larger than their A. operculatum equivalents, with just a single exception (the petB/atpA minicircle).

\section{Comparison of previously identified genes}

Coding regions on previously reported minicircles of $A$. operculatum and A. carterae had been identified by combination of BLAST searches and CodonPreference analysis of the DNA sequences. The 12 predicted gene-encoding regions in each species all have obvious identity to known chloroplast encoded proteins. The coding regions of $A$. operculatum and A. carterae minicircles show high levels of identity at both the DNA and predicted amino acid level
(Table 3). The PsaB sequences (beta subunit of Photosystem I) had the lowest identity between species, 97.6\%. All other inferred protein sequences have at least 99\% identity or above. Therefore, on the basis of their protein sequences it seems that the two dinoflagellate species are closely related. (In addition ultrastructural studies suggest that the A. operculatum strain might be more appropriately designated as A. carterae $\{\mathrm{E}$. Nash, pers. comm.\}) The shortest previously identified coding region is for PsbI, a component of Photosystem II, the sequence corresponding to protein of only 35 amino acids [13].

Little difference exists in the codon usage of the two Amphidinium species. Marked preferences exist for certain codons for many amino acid residues (data not shown). For example the GGT codon is by far the most frequently used codon for glycine. Other features of the codon usage in A. operculatum and H. triquetra have been discussed previously $[2,23]$.

An identical set of eleven codons is very infrequently used in both species (10 examples or fewer of each out of 4453 codons). They are TTA (Leu), TCA (Ser), TGA (Stop), CCC (Pro), CGC (Arg), CGG (Arg), ATA (Ile), ACG (Thr), AAA (Lys), AGA (Arg) and GGG (Gly). The frequency of the rare codons is unevenly distributed amongst the minicircle genes. The two genes for the core components of Photosystem I, psaA and $p s a B$, have higher frequencies of these codons than the other genes as shown in Table 4.

In addition to the previously identified protein genes BLAST searches identified a region with clear identity to a plastid-type LSU rDNA in each species of Amphidinium. However, the LSU rDNA sequence does not appear to be 
Table 2: Type and size of minicircle sequences in the chloroplast genomes studied

\begin{tabular}{|c|c|c|c|}
\hline & A. carterae & A. operculatum & H. triquetra \\
\hline total length (bp) & 45,815 & 34,186 & 42,769 \\
\hline mean GC content & $45.27 \%$ & $46.46 \%$ & $37.02 \%$ \\
\hline \multicolumn{4}{|l|}{ gene containing minicircles } \\
\hline psaA & 2,558 & 2,443 & 3,005 \\
\hline psaB & 2,366 & 2,363 & 3,121 \\
\hline psbA & 2,520 & 2,311 & 2,151 \\
\hline$p s b B$ & 2,327 & 2,282 & 2,286 \\
\hline$p s b C$ & 2,477 & 2,341 & 2,330 \\
\hline$p s b D / E / l$ & 2,358 & 2,369 & \\
\hline$p s b D$ & & & $2,628^{\#}$ \\
\hline psbE & & & $2,196^{\#}$ \\
\hline petB/atpA & 2,606 & 2,713 & \\
\hline petB & & & 2,204 \\
\hline atpA & & & 2,444 \\
\hline petD & 2,563 & 2,416 & $2,177 \#$ \\
\hline $\operatorname{atp} B$ & 2,587 & 2,483 & - \\
\hline LSU rRNA & 2,713 & 2,651 & 3,027 \\
\hline SSU rRNA & $(2,533)$ & $(2,458)$ & 2,563 \\
\hline \multicolumn{4}{|l|}{ 'empty' minicircles } \\
\hline No. & 10 & 5 & 1 \\
\hline total length of empty minicircles & $20,729(18,196 \$)$ & $9,825(7,367 \$)$ & $2,012^{\#}$ \\
\hline chimeric minicircles & & & 5 \\
\hline total length of chimeric minicircles & & & 10,625 \\
\hline
\end{tabular}

\$Not including putative SSU rRNA minicircle.

\#These sequences were submitted to the sequence database whilst this paper was in submission, the sequences do not therefore form part of our comparative analysis.

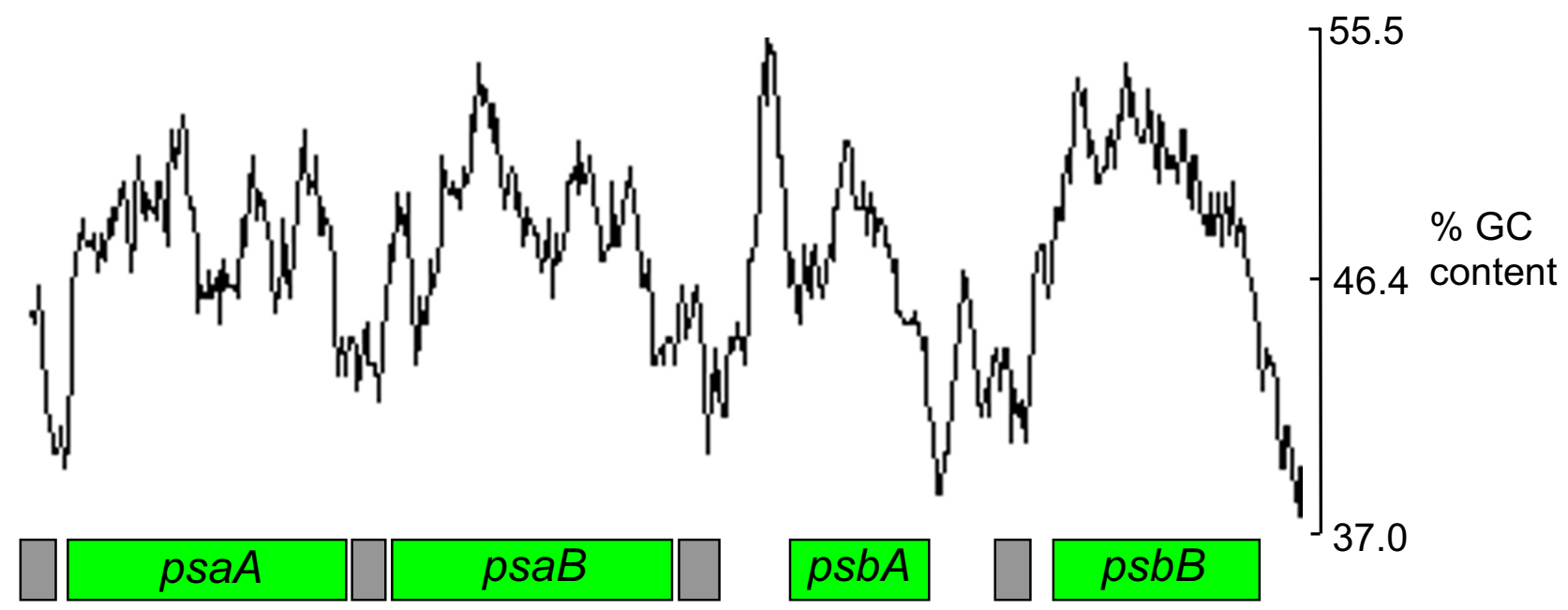

Figure I

GC content for the psaA-, psaB-, psbA- and psbB-containing minicircles of $A$. operculatum. GC content is calculated within a window of 200 nucleotides. Boxes indicate the positions of genes (green) and core regions (gray). 
Table 3: Percentage identities of minicircle ORFs

\begin{tabular}{lcc}
\hline & A. operculatum & H. triquetra \\
& percentage identities & percentage identities \\
\hline PsaA & 99.3 & 50.7 \\
PsaB & 97.6 & 42.7 \\
PsbA & 99.7 & 86.1 \\
PsbB & 100.0 & 59.9 \\
PsbC & 99.6 & 64.5 \\
PsbD & 99.7 & na \\
PsbE & 100.0 & na \\
Psbl & 100.0 & na \\
PetB & 99.1 & 75.3 \\
PetD & 100.0 & na \\
AtpA & 99.8 & 54.1 \\
AtpB & 99.3 & na \\
ORFI & 98.6 & na \\
ORF2 & 100.0 & na \\
ORF3 & 100.0 & na \\
LSU rRNA & 92.0 over 2662 base stretch, not all of this may be LSU rDNA. (DNA comparison) & \\
SSU rRNA & 81.1 over 2403 base stretch, not all of this may be SSU rDNA. (DNA comparison) & 69.8 over 288 base stretch. (DNA comparison) \\
\end{tabular}

Percentage identities were calculated by comparison to $A$. carterae sequences using pairwise Blast [36].

$\mathrm{na}$ - sequences unavailable or not found in the other species.

Table 4: Distribution of rare codons in Amphidinium minicircle protein genes.

\begin{tabular}{|c|c|c|c|c|c|c|}
\hline & A. c./no. & A. c./total amino acids & $\%$ rare codons & A. o./no. & A. o./total amino acids & $\%$ rare codons \\
\hline psaA & 16 & 678 & 2.4 & 13 & 671 & 1.9 \\
\hline psaB & 9 & 644 & 1.4 & 12 & 685 & 1.8 \\
\hline$p s b A$ & 4 & 340 & 1.2 & 2 & 340 & 0.6 \\
\hline$p s b B$ & 3 & 506 & 0.6 & 3 & 506 & 0.6 \\
\hline$p s b C$ & 5 & 463 & I.I & 5 & 463 & 1.1 \\
\hline$p s b D$ & 2 & 355 & 0.6 & I & 355 & 0.3 \\
\hline$p s b E$ & 0 & 77 & - & 0 & 77 & - \\
\hline psbl & 2 & 35 & 5.7 & I & 35 & 2.9 \\
\hline petB & 4 & 219 & 0.9 & 2 & 219 & 0.9 \\
\hline petD & 2 & 157 & 1.3 & 2 & 157 & 1.3 \\
\hline $\operatorname{atp} A$ & 4 & 488 & 0.8 & 4 & 488 & 0.8 \\
\hline $\operatorname{atp} B$ & 5 & 590 & 0.8 & 6 & 590 & 1.0 \\
\hline ORFI (psbD/E/l) & 3 & 73 & 4.1 & 3 & 73 & 4.1 \\
\hline ORF2 (petD) & 5 & 90 & 5.6 & 5 & 90 & 5.6 \\
\hline ORF3 (petD) & 9 & 150 & 6.0 & 8 & 150 & 5.3 \\
\hline
\end{tabular}

Rare codons comprise $1.2 \%$ of all codons in the previously identified gene set.

A. c.: Amphidinium carterae, A. o.: Amphidinium operculatum. 
a full-length sequence, as will be discussed later. No SSU rRNA gene was identified in an initial search in the Amphidinium sequences.

\section{Further protein genes}

Artemis and ACT analyses were used to identify regions of high identity between the Amphidinium species that were comparable in sequence identity to previously characterised genes (>95\%). Using Artemis ORFs within these regions were identified and investigated [see Additional files 1, 2, 3 and 4]. These comparative analyses suggest there may be a further three protein coding regions on the gene-coding minicircles; one more on the $p s b D / E / I$ minicircle and two more on the petD minicircle. The positions of these putative protein-coding regions are shown in Figure 2. The inferred amino acid sequences have relatively few of the 'rare' codons, as determined from the previously identified genes, though the occurrence of these codons is more frequent (Table 4). None of the putative amino acid sequences gave significant hits in BLAST and FASTA searches of protein databases. One of the sequences (the second ORF on the petD minicircle, ORF3) was suggested by FUGUE [24] to encode a ribosomal protein (Rpl15), although the assignment was tentative. An alignment of the ORF3 sequence with other Rpl15 sequences shows a very low level of identity with these sequences. A longer sequence, open apart from a single TAA termination codon, is present in a different reading frame. However, this did not give significant hits in BLAST or FASTA sequences. Furthermore, no evidence of editing has yet been found in Amphidinium [15], so we identify the most likely ORF as that shown in Figure 2b. Several other short ORFs are present in areas of minicircles that are neither established coding regions nor core regions. However, these ORFs are either not conserved between the Amphidinium species or have high levels of rare codons, and do not give significant hits in protein similarity searches.

Within the A. operculatum empty minicircles there is only a single ORF capable of producing a protein of over 100 amino acids on the expected strand in all the 'empty' circles. Six ORFs exist that could produce proteins of at least 75 amino acids. Numerous ORFs exist of comparable size to the psbI ORF. Within the A. carterae empty minicircles, where more 'empty' minicircles have been identified, three ORFs capable of producing a protein of over 100 amino acids are present on the expected strand together with a further eleven ORFs capable of producing proteins of at least 75 amino acids. However, none of these ORFs of over 75 amino acids is found in their entirety on an empty circle in both species. In some cases short stretches of sequence corresponding to part of these ORFs show high levels of identity (>90\%) between the species. However, in all these cases either the level of identity rapidly falls or frame shifts are introduced in one of the sequences.

One of the ORFs found only in A. carterae is of note in that it is predicted by the FUGUE search algorithm to be a ribosomal protein (Rps3) gene. The gene for this protein is invariably found in the plastid genome of all other plastid-containing organisms. So far the gene for this protein has not been found in any of the dinoflagellate EST projects, although it should be noted that these projects are not comprehensive with regard to plastid targeted gene sequences. Alignments with other Rps3 sequences are not conclusive in identifying the ORF. They suggest that the first domain of the protein, if it is an Rps3, is truncated.

\section{RNA genes}

Typically chloroplast genomes encode a number of important functional RNA molecules. These include tRNAs, rRNAs and in some taxa tmRNA, the RNA component of RNase $P$ and the RNA associated with the SRP-like protein. We carried out sensitive searches of regions of high identity (>90\%) between species to identify whether such components are encoded in the dinoflagellate chloroplast genome [see Additional files 1, 2, 3, 4, 5, and 6]. For the larger RNA molecules we attempted to establish their organisation and extent [see Additional files 7, 8, 9 and 10]. Typically this was achieved by using Bestfit to identify matches to short conserved nucleotide motifs that are found in the functional RNAs. Regions identified by this approach were checked against multiple alignments. Surrounding sequences were analysed to see if there was potential for forming appropriate secondary structures [see Additional files 11 and 12]. This was achieved using a combination of visual inspection and the Mfold program. In generating assignments we made extensive use of structure models, especially those of Gutell et al. for rRNAs [25].

\section{Ribosomal RNA}

Within the Amphidinium species only one sequence with significant identity to a functional RNA has been previously identified $[3,13]$, showing similarity to a LSU rRNA gene. However, based on similarity searches this did not appear to be a full-length LSU rDNA sequence. We studied the sequence further to establish the probable size of the LSU ribosomal sequence and whether the sequence conforms to structural models of other chloroplast LSU ribosomal RNAs [25]. This comparison revealed that stretches of nucleotides sharing identity to conserved regions of other chloroplast LSU rDNAs are found only for domains II, IV, V and VI on the LSU rDNA minicircles of A. carterae and A. operculatum [26]. Domains I and III appear to be either missing or so divergent that alignment with other LSU rRNA molecules proves impossible. Even the 
a)

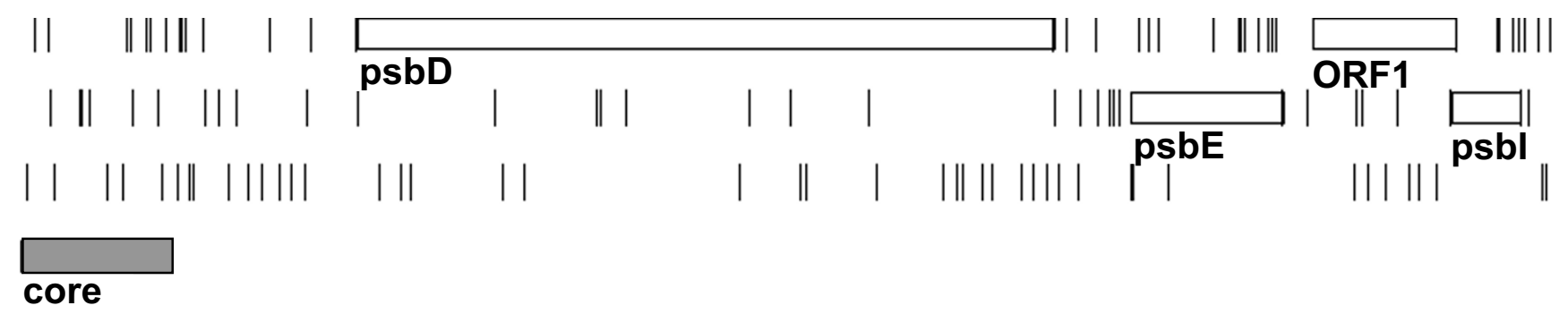

b)
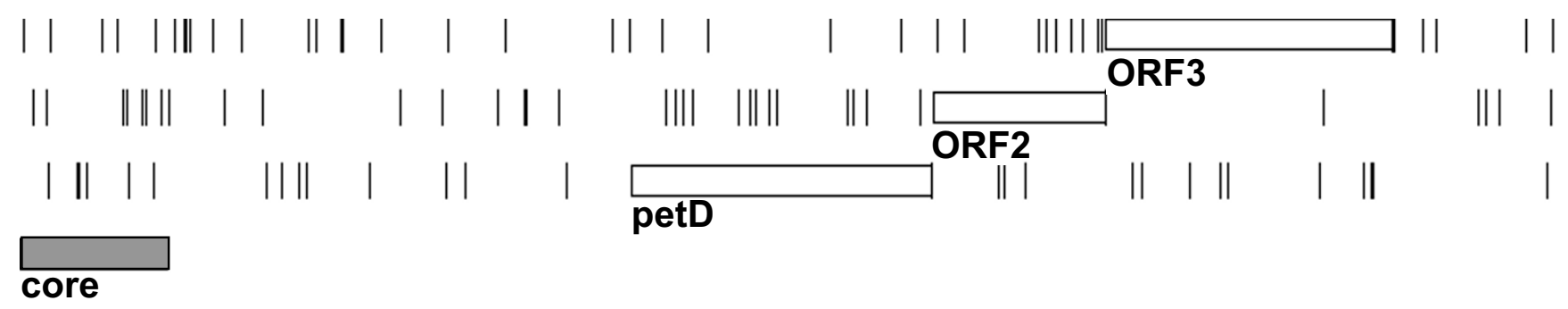

Figure 2

Positions of additional gene-coding regions. a) $p s b D E I$ minicircle of $A$. operculatum. A single further gene is proposed between the $p s b E$ and $p s b l$ genes. b) pet $D$ minicircle of $A$. operculatum. Two further genes are proposed following the pet $D$ gene. Diagrams show all three reading frames and the positions of all stop codons (vertical lines). Boxes indicate the positions of the proposed protein-coding regions and also the position of the core region on each minicircle. Minicircles were linearised for graphical display by breaking the minicircle immediately prior to the core region.

sequences which lie within the domains II, IV, V and VI are highly unusual compared with LSU rRNA genes from other chloroplasts. A higher substitution rate is apparent, and there is frequent deletion or truncation of helical elements (see Figure 3).

Only short stretches of domain II can be assigned. Many of the short stretches correspond to loop regions between helices (see Figure 3). The most notable feature that can be identified comprises helices 43 and 44. These helices are RNA components of the 'stalk', which is known to interact with elongation factors [26].

Domain IV is the most strongly conserved domain found. However, significant truncations of the sequence are clearly discernible. Helix 63 appears to have been completely lost. This is accompanied by a shortening of the following loop. Helix 66 appears to have been significantly modified and helix 68 is much shorter than is typical. Despite the Amphidinium sequences sharing fewer identities with other chloroplast ribosomal sequences than is usual, the overall folding of the molecule seems to be maintained.
Sequences corresponding to domain V are clearly discernible for both Amphidinium species. However, numerous truncations or mutations appear to have altered the capability of forming a typical structure. The truncations are almost exclusively found in regions corresponding to stem-loop structures, rather than the loop regions between stem-loops (Figure 3 ). In particular truncation of the region corresponding to helices 75-79 appears to be very extensive and an alternative folding is predicted that does not resemble more typical models. The nature of the sequence corresponding to domain $\mathrm{V}$, in terms of mutations and truncations, is similar to those described by Santos et al. in their study of domain V of LSU rDNA of the genus Symbiodinium [27].

The only feature of domain VI that can be assigned is the sarcin/ricin loop (helix 95). Identity to other LSU rDNA sequences break downs soon after this feature, and it is possible that this is where the functional sequence ends. It should be noted that the non-core sequence of $A$. operculatum microcircle 1 (415 bp) [13] corresponds almost exactly to the $23 \mathrm{~S}$ rRNA minicircle sequence after the end 


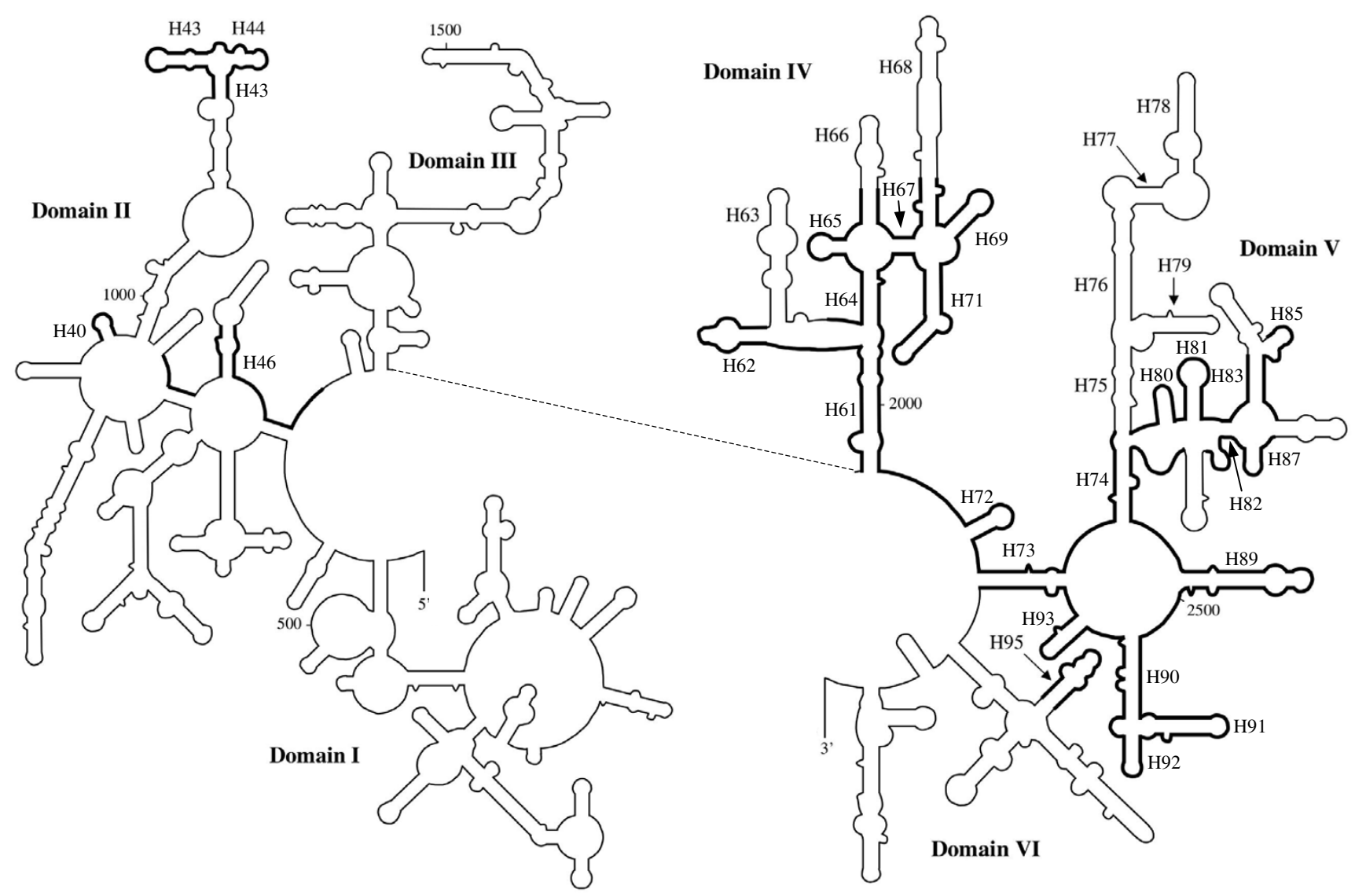

Figure 3

Schematic diagram indicating the extent of the LSU rRNA gene in Amphidinium. Structural model of the folding of the $5^{\prime}$ and 3' halves of LSU rRNA from E. coli. Regions where homologous sequence or structure is found on Amphidinium minicircles are in bold. The proposed base-pairing of the individual structures is displayed in additional file II, along with detailed numbering of the positions of the structures. Helices proposed to be present in Amphidinium or that are mentioned in the text are labelled (e.g. HI 8 for helix 18). Helix numbering as defined by Ban et al.[26].

of domain $\mathrm{V}$, including the region corresponding to the sarcin/ricin loop.

Short SSU rRNA sequences have previously been reported from empty circle 4, but they were believed to be nonfunctional owing to their length [15]. The surrounding sequences showed very low identity to other predicted SSU rDNAs; the first block of SSU rRNA sequence we identified is helix 18 (Figure 4). This feature contains the highly conserved 530 loop that is involved in proofreading of the mRNA/tRNA interaction [28]. The loop region itself shows high levels of identity with all other SSU rRNA sequences as shown in Figure 5. However, the sequence of the stem either side of the loop is very divergent with respect to other chloroplast SSU rRNAs (Figure 5). Indeed within this feature it appears to be the most divergent of all known chloroplast sequences. Despite the incorporation of these base changes base-pairing within the stem loop structure is maintained, suggesting selective evolutionary pressure is still present.

We found that there is a much larger intervening sequence between two of the elements that we identified (the 5' and 3 ' strands of helix 20 [Figure 4]) than is usually the case, 902 nucleotides rather than the 165 nucleotides (positions 588-753 E. coli [Figure 4]) that would be normally expected. None of the intervening sequences in Amphidinium resembled features typically found in SSU rRNAs. This suggests that the sequences preceding and following these elements could be transcribed separately or that an intron could be present.

The second block of SSU rRNA sequence we identified is much longer than the first and comprises sequences corresponding to positions 754-1542 (3' end) of the E. coli sequence. Despite having very low levels of identity to 


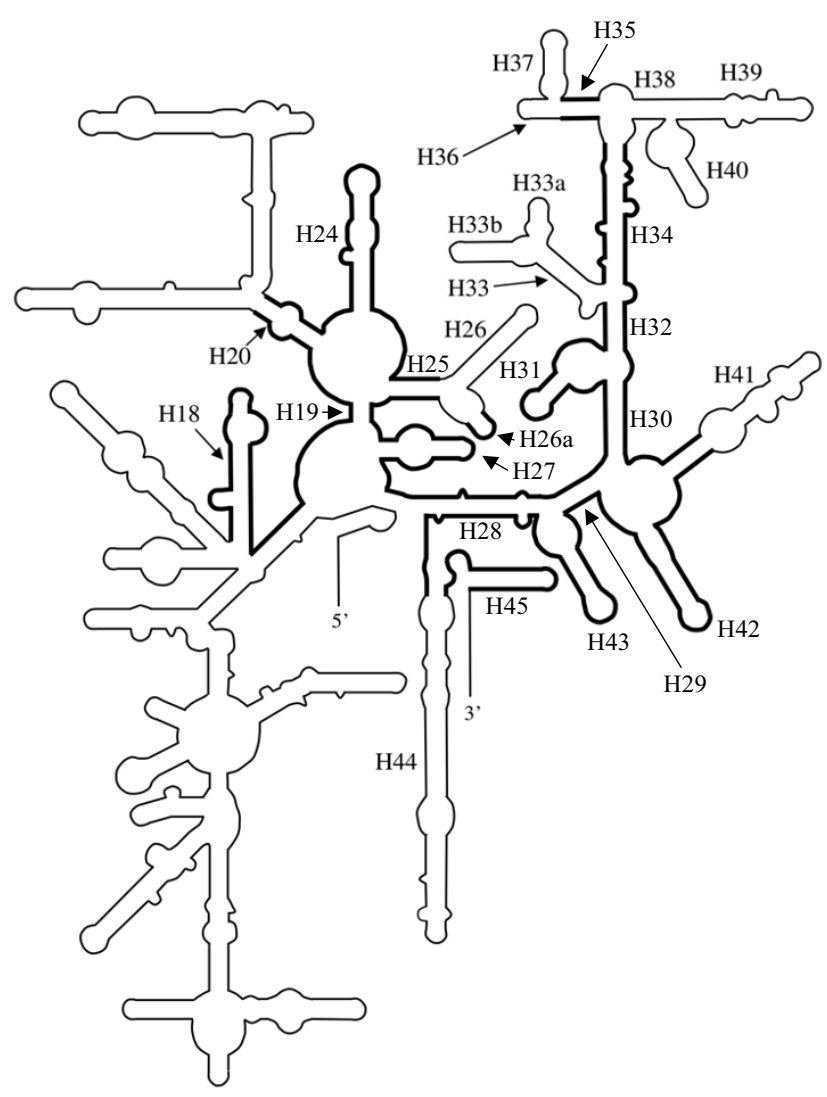

Figure 4

Schematic diagram indicating the extent of the LSU rRNA gene in Amphidinium. Structural model of the folding of the SSU rRNA from E. coli. Regions where homologous sequence or structure is found on Amphidinium minicircles are in bold. The proposed base-pairing of the individual structures is displayed in additional file 12 , along with detailed numbering of the positions of the structures. Helices proposed to be present in Amphidinium or that are mentioned in the text are labelled (e.g. H95 for helix 95). Helix numbering as defined by Wimberley et al. [28].

other SSU rDNAs the sequence is capable of folding to form most of the secondary structure elements found in such molecules. Some peripheral features do appear to have been lost or truncated, namely regions corresponding to helices 26, 33, 33a, 33b, 36, 37, 38, 39, 40 and 44 (see Figure 4).

We have found no evidence for a 5S rRNA gene.

The highly divergent nature of the LSU and SSU rDNA sequences raises the probability that they are pseudogenes rather than functional sequences. Clearly the rDNA sequences are unlike any that have been previously described from chloroplast genomes. Even the sequences from the apicoplasts of sporozoa, such as Toxoplasma gon- dii, whilst showing high levels of substitution have retained essentially all the structural features, including all the domains, found in other plastid rDNAs [25]. The closest example to the sequences found on dinoflagellate minicircles comes from highly derived mitochondrial genomes. In many mitochondrial rDNAs there are extensive examples of deletions and truncations of many structural elements including entire domains, as well as examples of fragmented rDNA sequences. In the most reduced examples peripheral features are extensively deleted whilst key regions which contribute to essential features such as the A, P and E sites are retained [29]. Our analyses suggests that this is what we find with regard to the dinoflagellate rDNA sequences. Nucleotide positions that are known to contribute to the A, P and E sites are generally well conserved in Amphidinium as well as other important features such as proof-reading and decoding sites. It is also possible that other rDNA fragments exist that "fill in" missing parts of the molecules. Thus the rRNAs could be assembled from separate bits, as has been found elsewhere (e.g. Chlamydomonas mitochondria [30]). The molecules could either remain separate or be joined together by trans-splicing.

We therefore carried out RT-PCR of representative regions of LSU and SSU rRNA. Using specific primers we amplified two regions for the predicted LSU rRNA; these corresponded to sequences from $3^{\prime}$ of helix 46 to $5^{\prime}$ of helix 62 and from $5^{\prime}$ of helix 62 to $5^{\prime}$ of helix 72 . For the SSU rRNA gene we amplified a region from $3^{\prime}$ of helix 27 to $5^{\prime}$ of helix 43. Precise primer positions are specified in the supplementary data files BMCGenLSU.tab and BMCGenSSU.tab respectively. For both RNAs products were obtained of sizes corresponding to genomic DNA (Figure 6 ), whose sequences were also consistent with the genomic DNA. These initial data indicate that the putative rRNA genes are transcribed and remain essentially unmodified.

\section{tRNA}

Searches for tRNAs in Amphidinium revealed a single putative example, which is present in both species. The sequence suggests that it is a formyl-methionine initiator tRNA, as there is an absence of Watson-Crick base pairing at the end of the acceptor stem and also there is a characteristic purine:pyrimidine base pair in the dihydrouridine stem, in contrast to a pyrimidine:purine base pair which is found in other tRNAs [31]. The predicted structure of the A. operculatum tRNA is shown in Figure 7a. The trnfM sequence is found adjacent to the 3 ' end of the core region on empty minicircle 4 in $A$. operculatum and empty minicircle 33 in A. carterae (both of which we now believe to contain the unusual SSU rRNA gene) and is almost completely identical between the two species. It may be significant that it is a $\operatorname{trnfM}$ sequence that is retained as no 
Plasmodium berghei

Babesia bovis

Cyanidium caldarum

Chondrus crispus

Emiliania huxleyi

Chlorarachnion sp.

Astasia longa

Euglena gracilis

Toxoplasma gondii

Pylaiella littoralis

Cyanophora paradoxa

Porphyra purpurea

Olisthodiscus luteus

Odontella sinensis

Nephroselmis olivacea

Chlorella vulgaris

Pyrenomonas salina

Guillardia theta

Cryptomonas phi

Prototheca zopfii

Chlamydomonas moewusii

Heterocapsa triquetra

Amphidinium operculatum

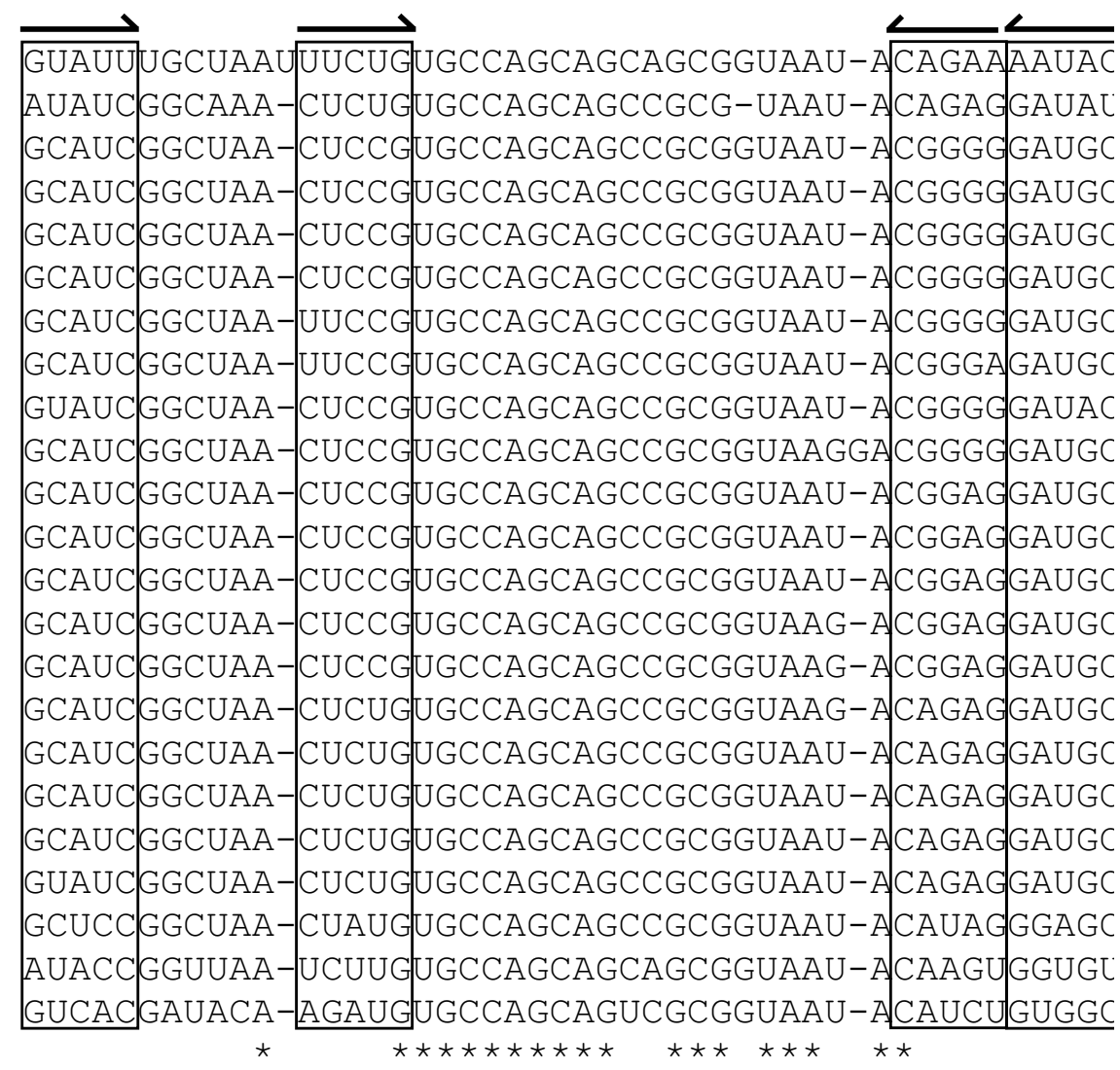

\section{Figure 5}

Alignment of chloroplast SSU rDNA sequences corresponding to helix 18. Boxes and arrows indicate regions of complementary base pairing. Asterisks indicate positions of nucleotide identity.

equivalent tRNA species exists in the cytosol which could be imported as a replacement [32]. Many organelles with highly reduced genomes lacking a full complement of tRNA genes are believed to import cytosolic tRNAs to maintain translation within the organelle [33].

A homologous fMet-tRNA was not found in any of the Heterocapsa species sequences, although two other putative tRNA sequences were found, one for Pro-tRNA and one for Trp-tRNA (Figure 7b, 7c respectively). In $\mathrm{H}$. triquetra both putative tRNA sequences are found on minicircles that do not have full-length gene sequences, but have truncated versions of at least two other genes ('jumbled' minicircles) [14]. One such circle carries a single tRNA gene, whilst in three others the two tRNAs are found in tandem. All of the tRNA sequences found on each of the different 'jumbled' minicircles are identical. In Heterocapsa pygmaea these two same tRNA sequences are found in tandem on $p s b A$ minicircles, almost immediately after the $p s b A$ coding region. Two distinct $p s b A$-containing minicircles have been isolated from H. pygmaea, and both contain the tRNA sequences. The tRNA sequences are almost identical to the $H$. triquetra sequences (Figure $7 \mathrm{~b}$, $6 \mathrm{c})$. Some sequence variation exists between the tRNA sequences on each of the minicircle in $H$. pygmaea. In one of the tandem tRNA copies (H. pygmaea 2$)$ this variation disrupts base-pairing in the tRNA structures (Figure 7b, 7c). As there are apparently at least two copies of the gene it is possible that one of the sequences is redundant and is no longer under selective pressure.

\section{Other RNA species}

Searches for other RNA species that have previously been discovered in other chloroplast genomes did not yield any significant matches. Thus we found no evidence for RNase $\mathrm{P}$, tmRNA or SRP-associated RNA.

\section{Conclusion}

The acquisition of complementary sets of minicircles from two Amphidinium species has facilitated the identification of several genetic features on the minicircles that had not previously been recognised. We suggest that a further three protein coding genes are present on the minicircular chloroplast genome of both A. operculatum and A. carterae. 


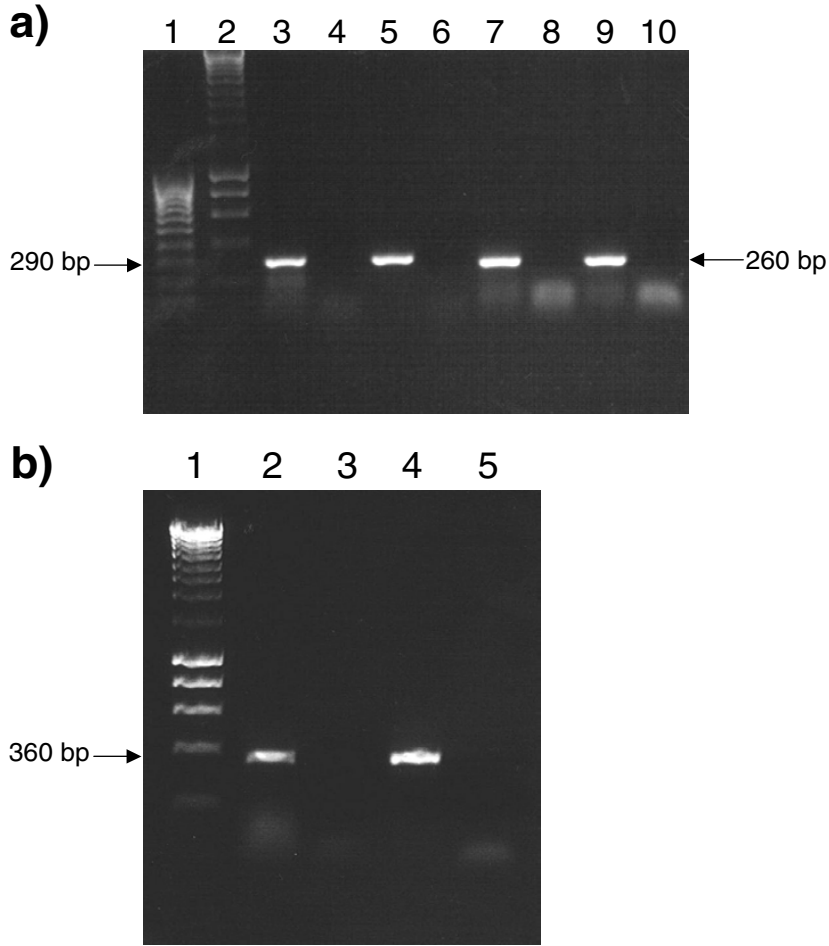

\section{Figure 6}

RT-PCR analysis of LSU and SSU rRNA sequences. a) Lane I, Hyperladder IV markers (Bioline); Lane 2, Hyperladder I markers (Bioline); Lane 3, RT-PCR with primers LSUIF and LSU2R and A. operculatum RNA template; Lane 4, as Lane 3 but no RT enzyme; Lane 5, PCR with primers LSUIF and LSU2R and A. operculatum DNA template; Lane 6, as Lane 5 but no DNA template added; Lane 7, RT-PCR with primers LSU3F and LSU4R and A. operculatum RNA template; Lane 8, as Lane 7 but no RT enzyme; Lane 9, PCR with primers LSU3F and LSU4R and A. operculatum DNA template; Lane 10, as Lane 9 but no DNA template added. b) Lane I, Hyperladder I markers (Bioline); Lane 2, RT-PCR with primers SSUIF and SSU2R and A. operculatum RNA template; Lane 3, as Lane 2 but no RT enzyme; Lane 4, PCR with primers SSUIF and SSU2R and A. operculatum DNA template; Lane 5, as Lane 4 but no DNA template added.

These genes appear do not bear similarity to typically chloroplast genome located genes. They may therefore be specific to dinoflagellates and could be connected to the unusual genome organisation. Evidence from transcripts levels in $A$. carterae suggests that these open reading frames are expressed at levels comparable to other genes that have been found on minicircles such as $p s b D$ ( $R$. Hiller, in preparation).

We have also been able to locate a partial SSU rRNA gene. This was found on what had previously been described as
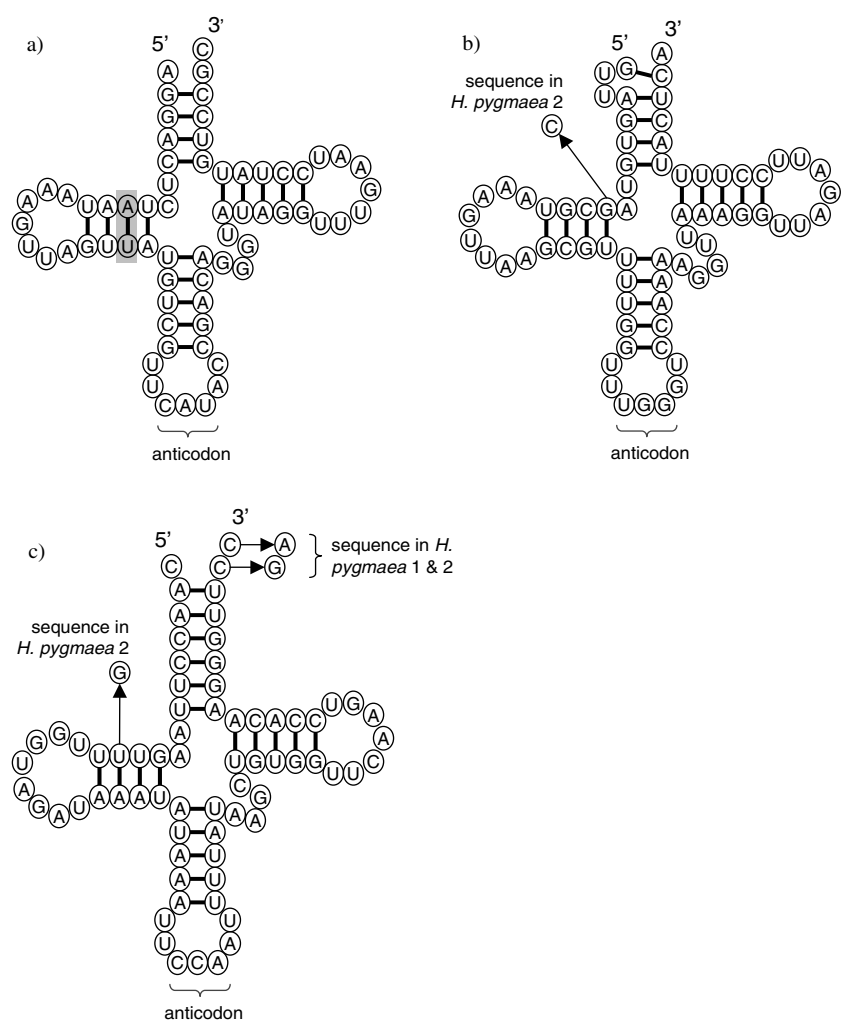

Figure 7

Structural diagrams of tRNA sequences found on minicircles of peridinin-containing dinoflagellates. Sequence variation between species or different copies within a species is indicated. Structures are as suggested by tRNAscan-SE v.l.2. a) Structure of the tRNA fMet encoded on empty circle 4 (ecao4: AF401630) in the dinoflagellate Amphidinium operculatum. The purine:pyrimidine base pair in the dihydrouridine stem characteristic of fMet-tRNAs is highlighted [3I]. b) Structure of the tRNAPro encoded on plastid minicircles in the dinoflagellates $H$. triquetra and $H$. pygmaea (H. pygmaea I: AF206707, H. pygmaea 2: AY033400). c) Structure of the tRNATrp encoded on plastid minicircles in the dinoflagellates $H$. triquetra and $H$. pygmaea.

empty minicircles in both Amphidinium species. With the exception of one further minicircle from A. carterae we have not found genes on any of the other empty minicircles, though their presence cannot yet be ruled out. It is possible that editing might restore presently unrecognized coding sequences. Although editing has been reported from $C$. horridum, no evidence has been found for it in Amphidinium, although only a limited number of transcripts have been tested [15]. We determined the extent of the both the SSU rRNA and LSU rRNA genes by sequence and folding similarity to other chloroplast genes. This 
revealed the extremely unusual nature of these genes. Numerous features of the chloroplast rRNA molecules are missing from these sequences, including whole domains in the case of the LSU rDNA. It is possible that these domains could be transcribed from a distinct DNA locus and the rRNA reassembled post-transcriptionally. However, the RT-PCR data suggest that this is not the case. Further transcript analysis will be needed to confirm this, but it seems that the extent and architecture of the Amphidinium sequences most closely resembles the severely truncated rDNAs found in some mitochondrial genomes, and represents the most divergent chloroplast rDNAs yet found.

We also report the discovery of the first tRNA genes to be found on minicircles. These appear to be very limited in number and it is therefore likely that the peridinin-containing chloroplast is reliant on the import of cytosolic tRNAs for chloroplast translation. It is interesting that the only tRNA to be found so far in the Amphidinium species is an fMet-tRNA for which a cytosolic counterpart does not exist. It has been suggested that the plastid provides fMet-tRNA for the mitochondrion in Apicomplexa [32]. Although no complete dinoflagellate mitochondrial genome sequence has yet been published, no tRNA genes have been identified in the partial sequences available at present [34]. Given this, we suggest that the dinoflagellate plastid likewise supplies fMet-tRNA to the mitochondrion.

Our analyses further highlight the unusual nature of the peridinin-containing dinoflagellate chloroplast genome, which is characterised by highly reduced gene content, atypical genomic organisation and highly divergent gene sequences. However, the existence of divergent genes sequences may have lead us to underestimate the genetic capacity of the minicircular genomes, when they are examined in isolation. Comparative analyses of the dinoflagellate genomes, particularly closely related genomes, appear to be a useful tool in identifying significant features. Based on our analyses of the Amphidinium genomes the minicircles may be more densely packed with genes than we thought. Further comparative analyses of other dinoflagellate chloroplast genomes are likely to be useful.

\section{Methods}

\section{Culture Conditions}

A. carterae CS21 was cultured under continuous illumination $\left(20 \mu\right.$ Einsteins. $\left.\mathrm{m}^{-2} \cdot \mathrm{s}^{-1}\right)$ at $18^{\circ} \mathrm{C}$ in Provasoli's enriched sea water. A. operculatum (from the Culture Collection of Algae and Protozoa, Oban, UK, ref CCAP 1102/ 6 ) was cultured under a $16 \mathrm{~h}$ light $\left(25 \mu\right.$ Einsteins. $\left.\mathrm{m}^{-2} \cdot \mathrm{s}^{-1}\right) /$ $8 \mathrm{~h}$ dark cycle at $21^{\circ} \mathrm{C}$ in $\mathrm{f} / 2$ media.

\section{DNA Isolation, PCR amplification and cloning of minicircular sequences}

Template DNA for PCR was obtained from total DNA from A. carterae as described by Hiller[3]. Primers used in PCR reactions are described in Table 1 . Standard PCR conditions were an initial cycle of $94^{\circ} \mathrm{C}$ for 1 minutes followed by 35 cycles of $94^{\circ} \mathrm{C}$ for 1 minutes, $52^{\circ} \mathrm{C}$ for 1 minutes, $72^{\circ} \mathrm{C}$ for 4 minutes. PCR products were cloned into pGEM-T plasmid vector (Promega) and transformed into Escherichia coli prior to sequencing.

\section{DNA Sequencing and Computational Analysis of Sequences}

DNA clones were sequenced using the automatic dye terminator system (ABI 377). BLAST analyses were used to identify conserved chloroplast genes. Minicircle DNA sequences were assembled and analyzed using the GCG Wisconsin package (version 11.1, Accelrys Inc., San Diego, CA). The Bestfit, Compare, Dotplot and Gap programs, which are part of the GCG Wisconsin package, were used to identify regions of identity between minicircle sequences.

\section{Accession numbers of sequences used}

Amphidinium operculatum sequences used were: psaA [EMBL:AJ250264]; psaB [EMBL:AJ582639]; psbA [EMBL:AJ250262]; psbB [EMBL:AJ250263]; psbC [GenBank:AF426172]; psbD/E/I [EMBL:AJ620761]; petB/atpA [GenBank:AY048664]; petD [EMBL:AJ250265]; atpB [EMBL:AJ250266]; LSU rRNA [EMBL:AJ582640]; ecao4 (SSU rRNA) [GenBank:AF401630]; ecao1 (empty circle A. operculatum 1) [GenBank:AF401627]; ecao2 [Gen-

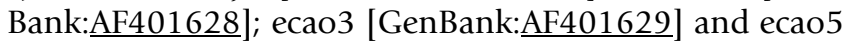
[EMBL:AJ582641].

Amphidinium carterae sequences used were: $p s a A$ [EMBL:AJ311631]; psaB [EMBL:AJ311629]; psbA [EMBL:AJ311632]; psbB [Genbank:DQ507216]; psbC [GenBank:DQ507219]; psbD/E/I [EMBL:J311628]; petB/ atpA [EMBL:AJ311630]; petD [GenBank:DQ507217]; atpB [GenBank:DQ507218]; LSU rRNA [EMBL:AJ311633]; ecac33 (SSU rRNA) [EMBL:AJ318067]; ecac2 (empty circle A. carterae 2) [EMBL:AJ307009]; ecac10 [EMBL:AJ307010]; ecac11 [EMBL:AJ307011]; ecac14 [EMBL:AJ307012]; ecac15 [EMBL:AJ307014]; ecac17 [EMBL:AJ307013]; ecac25 [EMBL:AJ307015]; ecac27 [GenBank:DQ507216] and ecac82 [EMBL:시307016].

Heterocapsa triquetra sequences used were: psaA [GenBank:AF130031]; psaB [GenBank:AF130032]; psbA [GenBank:AF130033]; psbB [GenBank:AF130034]; psbC [GenBank:AF130035]; petB [GenBank:스130037]; atpA [GenBank:AF130036]; LSU rRNA [GenBank:AF130039]; SSU rRNA [GenBank:AF130038]; abc1 (aberrant circle 1) [GenBank:AY004267]; abc2 [GenBank:AY004268]; abc3 
[GenBank:AY004269]; abc4 [GenBank:AY004270] and abc5 [GenBank:ㅅ004271].

Heterocapsa pygmaea sequences used were: psbA [GenBank:AF206707] and psbA2 [GenBank:AY033400].

\section{Artemis and ACT analysis}

Artemis and Artemis Comparison Tool (ACT) were used for whole genome analyses of minicircle sequences $[35,36]$. For these analyses minicircle sequences were concatenated as linear DNA sequences. The circular sequences were linearised by breaking immediately $5^{\prime}$ of the core region. The sequence and annotation files for use with Artemis are available as additional files in this publication [See Additional files 1, 2, 3, 4, 5, 6, 7, 8, 9, 10]. ACT was used to visualise regions of identity between species. Regions of identity were determined by pairwise Blast [37]. The output of the pairwise Blast was then used as an input into ACT.

\section{RNA searches}

Identification of potential structures of rRNA was facilitated by comparison of the dinoflagellate sequences to structural models of rRNAs. These were obtained from the Comparative RNA website [25]. Potential folding of inferred RNA sequences was explored using Mfold [38]. Searches for potential tRNA sequences were carried out with tRNAscan-SE v.1.2 using a mitochondrial/chloroplast source model [22]. The tmRNA website was used for similarity searches between a database of tmRNAs and the dinoflagellate sequences [39].

\section{RNA extraction and RT-PCR analysis}

Template RNA for reverse transcriptase reactions was obtained from A. operculatum cells using the RNeasy Mini Kit (QIAGEN) according to manufacturer's instructions. Total RNA was subsequently incubated with RQ RNasefree DNase (Promega) for 1 hour at $37^{\circ} \mathrm{C}$, after which $5 \mu \mathrm{l}$ STOP solution was added and the DNase inactivated by incubation at $65^{\circ} \mathrm{C}$ for 10 minutes. For first-strand DNA synthesis $5 \mu \mathrm{l}$ RNA preparation was mixed with $20 \mathrm{pmol}$ of the relevant RT primer in a total volume of $15 \mu \mathrm{l}$. This mixture was incubated at $70^{\circ} \mathrm{C}$ for 5 minutes then rapidly cooled on ice. To this initial volume $5 \mu \mathrm{l}$ of MoloneyMurine Leukemia Virus RT reaction buffer (Promega), $1.25 \mu \mathrm{l}$ of dNTPs (10 mM each), $25 \mathrm{U}$ of RNasin (Promega) and $200 \mathrm{U}$ of Moloney-Murine Leukemia Virus reverse transcriptase (M-MLV RT) were added and the reaction mixture brought to $25 \mu \mathrm{l}$ with nuclease-free water. The reverse transcription reaction was incubated at $42^{\circ} \mathrm{C}$ for 1 hour. Controls with no M-MLV RT added were also performed. Subsequent PCR was carried out using 5 $\mu \mathrm{l}$ of the reverse transcription reaction mixture to which $25 \mu$ l MasterAmp 2× PCR Premix A (Epicentre Technologies), $2 \mu \mathrm{l} 25 \mathrm{mM} \mathrm{MgCl}_{2}$, $25 \mathrm{pmol}$ of each primer and 1.25
U GoTaq DNA polymerase (Promega) were added and the reaction mixture brought to $50 \mu \mathrm{l}$. Standard PCR conditions were an initial cycle of $95^{\circ} \mathrm{C}$ for 2 minutes followed by 35 cycles of $95^{\circ} \mathrm{C}$ for 1 minute, $52^{\circ} \mathrm{C}$ for 1 minute, $72^{\circ} \mathrm{C}$ for 1 minute and a final cycle of $72^{\circ} \mathrm{C}$ for $10 \mathrm{~min}$ utes. Positive controls which included A. operculatum total DNA instead of M-MLV RT reaction mix and negative controls with no template addition were also carried out as well as the no M-MLV RT control described above. PCR products obtained were cloned into pGEM-T Easy plasmid vector (Promega) and transformed into Escherichia coli prior to sequencing.

\section{Authors' contributions}

ACB helped conceive the study, carried out all the in silico analyses and drafted the manuscript. NS and RH jointly carried out PCR amplifications of minicircle genes from $A$. carterae and sequenced the products. LJP carried out the RT-PCR experiments. CJH helped conceive the study, participated in its direction and helped draft the manuscript. All authors read and approved the final manuscript.

\section{Additional material}

\section{Additional File 1}

A. carterae Artemis sequence file. Plain text file containing concatenated A. carterae minicircle sequences for viewing with Artemis a freely available genome viewer and annotation tool.

Click here for file

[http://www.biomedcentral.com/content/supplementary/14712164-7-297-S1.dna]

\section{Additional File 2}

A. operculatum Artemis sequence file. Plain text file containing concatenated A. operculatum minicircle sequences for viewing with Artemis a freely available genome viewer and annotation tool.

Click here for file

[http://www.biomedcentral.com/content/supplementary/1471-

2164-7-297-S2.dna]

\section{Additional File 3}

$\mathrm{H}$. triquetraArtemis sequence file. Plain text file containing concatenated $\mathrm{H}$. triquetra minicircle sequences for viewing with Artemis a freely available genome viewer and annotation tool.

Click here for file

[http://www.biomedcentral.com/content/supplementary/14712164-7-297-S3.dna]

\section{Additional File 4}

A. operculatum Artemis annotation file. Artemis annotation file for use with additional file 1. Contains gene location information.

Click here for file

[http://www.biomedcentral.com/content/supplementary/14712164-7-297-S4.tab] 


\section{Additional File 5}

A. operculatum Artemis annotation file. Artemis annotation file for use with additional file 2. Contains gene location information.

Click here for file

[http://www.biomedcentral.com/content/supplementary/1471-

2164-7-297-S5.tab]

\section{Additional File 6}

H. triquetra Artemis annotation file. Artemis annotation file for use with additional file 3. Contains gene location information.

Click here for file

[http://www.biomedcentral.com/content/supplementary/1471-

2164-7-297-S6.tab]

\section{Additional File 7}

A. operculatum LSU minicircle Artemis sequence file. Plain text file containing A. operculatum LSU $r R N A$ minicircle sequence for viewing with Artemis, a freely available genome viewer and annotation tool. Click here for file

[http://www.biomedcentral.com/content/supplementary/14712164-7-297-S7.dna]

\section{Additional File 8}

A. operculatum LSU minicircle Artemis annotation file. Artemis annotation file for use with additional file 7 . Contains predicted locations of LSU rRNA structures (helices and loops) found on the A. operculatum LSU rRNA minicircle.

Click here for file

[http://www.biomedcentral.com/content/supplementary/1471-

2164-7-297-S8.tab]

\section{Additional File 9}

A. operculatum SSU minicircle Artemis sequence file. Plain text file containing A. operculatum SSU rRNA minicircle sequence for viewing with Artemis, a freely available genome viewer and annotation tool. Click here for file

[http://www.biomedcentral.com/content/supplementary/14712164-7-297-S9.dna]

\section{Additional File 10}

A. operculatum SSU minicircle Artemis annotation file. Artemis annotation file for use with additional file 9. Contains predicted locations of SSU rRNA structures (helices and loops) found on the A. operculatum SSU rRNA minicircle.

Click here for file

[http://www.biomedcentral.com/content/supplementary/14712164-7-297-S10.tab]

\section{Additional File 11}

A. operculatum LSU rRNA structures. Word document containing proposed RNA structures found on the A. operculatum LSU rRNA minicircle with detailed base-pairing and numbering.

Click here for file

[http://www.biomedcentral.com/content/supplementary/14712164-7-297-S11.doc]

\section{Additional File 12}

A. operculatum SSU rRNA structures. Word document containing proposed RNA structures found on the A. operculatum SSU rRNA minicircle with detailed base-pairing and numbering.

Click here for file

[http://www.biomedcentral.com/content/supplementary/1471-

2164-7-297-S12.doc]

\section{Acknowledgements}

We thank Frank Sharples for algal culture and Ellen Nisbet, Lila Koumandou and Saul Purton for helpful discussions. The BBSRC, the Leverhulme Trust, Churchill College and Macquarie University supported this work financially. This research was in accordance with the regulations of the Commonwealth of Australia, the State of New South Wales and Macquarie University governing the use of genetically modified organisms and recombinant DNA.

\section{References}

I. Zhang Z, Green BR, Cavalier-Smith T: Single gene circles in dinoflagellate chloroplast genomes. Nature 1999, 400:155-159.

2. Barbrook AC, Howe CJ: Minicircular plastid DNA in the dinoflagellate Amphidinium operculatum . Mol Gen Genet 2000, 263:152-158

3. Hiller RG: 'Empty' minicircles and petB/atpA and psbD/psbE $\left(c_{t} b_{559} \alpha\right)$ genes in tandem in Amphidinium carterae plastid DNA. FEBS Lett 200I, 505:449-452.

4. Laatsch T, Zauner S, Stoebe-Maier B, Kowallik KV, Maier U-G: Plastid-derived single gene minicircles of the dinoflagellate Ceratium horridum are localized in the nucleus. Mol Biol Evol 2004, 21:1318-1322.

5. Nelson MJ, Green BR: Double hairpin elements and tandem repeats in the non-coding region of Adenoides eludens chloroplast gene minicircles. Gene 2005, 358: I02-II 0.

6. Koumandou VL, Nisbet RER, Barbrook AC, Howe CJ: Dinoflagellate chloroplasts - where have all the genes gone? Trends Genet 2004, 20:261-267.

7. Hackett JD, Yoon HS, Soares MB, Bonaldo MF, Casavant TL, Nosenko $T$, Bhattacharya D: Migration of the plastid genome to the nucleus in a peridinin dinoflagellate. Curr Biol 2004, I 4:2 I 3-2 I8.

8. Bachvaroff TR, Concepcion GT, Rogers CR, Herman EM, Delwiche $C$ : Dinoflagellate expressed sequence tag data indicate massive transfer of chloroplast genes to the nuclear genome. Protist 2004, 155:65-78.

9. Tanikawa N, Akimoto H, Ogoh K, Chun W, Ohmiya Y: Expressed sequence tag analysis of the dinoflagellate Lingulodinium polyedrum during dark phase. Photochem Photobiol 2004, 80:3 I-35.

I0. Patron NJ, Waller RF, Archibald JM, Keeling PJ: Complex protein targeting to dinoflagellate plastids. J Mol Biol 2005, 348: $1015-1024$.

II. Wang Y, Morse D: The plastid-encoded psbA gene in the dinoflagellate Gonyaulax is not encoded on a minicircle. Gene 2006, 37I:206-2I0.

12. Simpson CL, Stern DB: The treasure trove of algal chloroplast genomes. Surprises in architecture and gene content, and their functional implications. Plant Physiol 2002, 129:957-966.

13. Nisbet RER, Koumandou VL, Barbrook AC, Howe CJ: Novel plastid gene minicircles in the dinoflagellate Amphidinium operculatum. Gene 2004, 331: | 41-147.

14. Zhang Z, Cavalier-Smith T, Green BR: A family of selfish minicircular chromosomes with jumbled chloroplast gene fragments from a dinoflagellate. Mol Biol Evol 200I, 18:I558- 1565.

15. Barbrook AC, Symington H, Nisbet RER, Larkum A, Howe C]: Organisation and expression of the plastid genome of the dinoflagellate Amphidinium operculatum. Mol Genet Genomics 200I, 266:632-638.

16. Zhang Z, Cavalier-Smith T, Green BR: Evolution of dinoflagellate unigenic minicircles and the partially concerted divergence of their replicon origins. Mol Biol Evol 2002, 19:489-500. 
17. Takashita K, Ishikura M, Koike K, Maruyame $T$ : Comparison of phylogenies based on nuclear-encoded SSU rDNA and plastid-encoded psbA in the symbiotic dinoflagellate genus Symbiodinium. Phycologia 2003, 42:2850-29l.

18. Wang $Y$, Jensen L, Højrup P, Morse D: Synthesis and degradation of dinoflagellate plastid-encoded psbA proteins are light-regulated, not circadian-regulated. Proc Natl Acad Sci USA 2005, 102:2844-2849.

19. Hayashi T, Makino K, Ohnishi M, Kurokawa K, Ishii K, Yokoyama K, Han C-G, Ohtsubo E, Nakayama K, Murata T, Tanaka M, Tobe T, lida T, Takami H, Honda T, Sasakawa C, Ogasawara N, Yasunaga T, Kuhara S, Shiba T, Hattori M, Shinagawa H: Complete genome sequence of enterohemorrhagic Escherichia coli 0 157:H7 and genomic comparison with a laboratory strain K-12. DNA Res 200I, 8: II-22

20. Kawai M, Uchiyama I, Kobayashi I: Genome comparison in silico in Neisseria suggests integration of filamentous bacteriophages by their own transposase. DNA Res 2005, I 2:389-40I.

21. Zhang Z, Green BR, Cavalier-Smith T: Phylogeny of ultra-rapidly evolving dinoflagellate chloroplast genes: a possible common origin of sporozoan and dinoflagellate plastids. J Mol Evol 2000, $51: 26-40$.

22. Lowe TM, Eddy SR: tRNAscan-SE: a program for improved detection of transfer RNA genes in genomic sequence. Nuc Acids Res 1997, 25:955-964.

23. Howe Cl, Barbrook AC, Koumandou VL, Nisbet RER, Symington $H$, Wightman TF: Evolution of the chloroplast genome. Phil Trans $R$ Soc Lond B 2002, 358:99-107.

24. Shi J, Blundell TL, .Mizuguchi K: FUGUE: sequence-structure homology recognition using environment-specific substitution tables and structure-dependent gap penalties. I Mol Biol 200I, 3 I 0:243-257.

25. Cannone JJ, Subramanian S, Schnare MN, Collett JR, D'Souza LM, Du Y, Feng B, Lin N, Madabusi LV, Müller KM, Pande N, Shang Z, Yu N, Gutell RR: The comparative RNA web (CRW) site: an online database of comparative sequence and structure information for ribosomal, intron, and other RNAs. BMC Bioinformatics 2002, 3:2.

26. Ban N, Nissen P, Hansen J, Moore PB, Steiz TA: The complete atomic structure of the large ribosomal subunit at $2.4 \mathrm{~A}$ resolution. Science 2000, 289:905-920.

27. Santos SR, Taylor DJ, Kinzie RA III, Sakai K, Coffroth MA: Evolution of length variation and heteroplasmy in the chloroplast rDNA of symbiotic dinoflagellates (Symbiodinium, Dinophyta) and a novel insertion in the universal core region of the large subunit rDNA. Phycologia 2002, 4I:3II-3I8.

28. Wimberley BT, Brodersen DE, Clemons WM Jr, Morgan-Warren RJ, Carter AP, Vonrheln C, Hartsch T, Ramakrishnan V: Structure of the 30 S ribosomal subunit. Nature 2000, 407:327-339.

29. Mears JA, Cannone JJ, Stagg SM, Gutell RR, Agrawal RJ, Harvey SC: Modelling a minimal ribosome based on comparative sequence analysis. J Mol Biol 2002, 321:2I5-234.

30. Burger G, Gray MW, Lang BF: Mitochondrial genomes: anything goes. Trends Genet 2003, 19:709-716.

31. RajBhandary UL: Initiator transfer RNAs. J Bacteriol 1994, I 76:547-552

32. Barbrook AC, Howe CJ, Purton S: Why are plastid genomes retained in non-photosynthetic organisms? Trends Plant $\mathrm{Sci}$ 2006, II:I0I-108.

33. Schneider A, Marechal-Drouard L: Mitochondrial tRNA import: are there distinct mechanisms? Trends Cell Biol 2000, 10:509-513.

34. Gray MW, Lang BF, Burger G: Mitochondria of protests. Ann Rev Genet 2004, 38:477-524.

35. Berriman $M$, Rutherford $K$ : Viewing and annotating sequence data with Artemis. Brief Bioinform 2003, 4: I 24-I32.

36. Carver T], Rutherford KM, Berriman M, Rajandream MA, Barrell BG Parkhill J: ACT: the Artemis Comparison Tool. Bioinformatics 2005, $21: 3422-3423$.

37. Tatusova TA, Madden TL: Blast 2 sequences - a new tool for comparing protein and nucleotide sequences. FEMS Microbiol Lett 1999, 174:247-250.

38. Zuker M: Mfold web server for nucleic acid folding and hybridization prediction. Nucleic Acids Res 2003, 31:3406-34I5.
39. Gueneau de Novoa P, Williams KP: The tmRNA website: reductive evolution of tm RNA in plastids and other endosymbionts. Nucleic Acids Res 2004, 32:D I04-DI08.
Publish with BioMed Central and every scientist can read your work free of charge

"BioMed Central will be the most significant development for disseminating the results of biomedical research in our lifetime. "

Sir Paul Nurse, Cancer Research UK

Your research papers will be:

- available free of charge to the entire biomedical community

- peer reviewed and published immediately upon acceptance

- cited in PubMed and archived on PubMed Central

- yours - you keep the copyright 